\title{
Closure of an oroantral fistula with a bone fragment during surgical extraction of an impacted maxillary second premolar: A case report
}

\author{
You-Song Sim¹, Seunggon Jung ${ }^{2}$, Hong-Ju Park ${ }^{3}$, and Min-Suk Kook ${ }^{3 *}$ \\ ${ }^{1}$ Resident, Department of Oral and Maxillofacial Surgery, School of Dentistry, Chonnam National University, Gwangju, Republic of Korea \\ ${ }^{2}$ Associate Professor, Department of Oral and Maxillofacial Surgery, School of Dentistry, Chonnam National University, Gwangju, Republic of Korea \\ ${ }^{3}$ Professor, Department of Oral and Maxillofacial Surgery, School of Dentistry, Chonnam National University, Gwangju, Republic of Korea
}

Maxillary sinus membrane perforation commonly occurs during extraction, mostly during an impacted tooth extraction. If left untreated, maxillary sinus perforation can cause several complications. Here, we describe a closure technique of an oroantral fistula using a bone fragment. During the extraction of an impacted maxillary second premolar, the tooth fell into the maxillary sinus. The tooth was removed from the sinus using a transantral approach. A bone fragment of the tooth was obtained and placed in the extraction socket via the transantral entrance and fixed with fibrin glue (Greenplast; Green Cross, Yongin, Korea) to close the oroantral fistula. After 5 months, an immature bone was formed in the sealed area where the bone graft was placed, without any complications.

Key Words: Fibrin tissue adhesive, Maxillary sinus membrane, Transantral approach

(c) This is an open-access article distributed under the terms of the Creative Commons Attribution Non-Commercial License (http://creativecommons.org/licenses/by-nc/4.0) which permits unrestricted noncommercial use, distribution, and reproduction in any medium, provided the original work is properly cited.

\section{Introduction}

Tooth impaction is commonly diagnosed with varying severity and diversity of location. It is rare in premolars and occurs mainly in the mandible rather than in the maxilla $[1,2]$. Orthodontic retraction can guide an impacted tooth to erupt normally [3]. However, if left untreated, tooth impaction can lead to esthetic problems, decreased masticatory efficiency, poor oral hygiene, and cyst formation. Particularly, impacted maxillary premolars often require surgical management, as maxillary premolars lie adjacent to the nasal cavity and maxillary sinus [4].

The dislocation of a tooth or its root into the maxillary sinus is common. Luxation of the palatal root of the maxillary first molar into the maxillary sinus occurs frequently. In such cases, radiography and evaluation of signs of maxillary perforation are essential [5]. Examination of the possible complications is recommended rather than extraction of a dislocated tooth with an uninfected root within the size of 2-3 mm. In cases of teeth with a larger root, extraction is recommended for dislocation of the infected root or the whole tooth. Teeth can be extracted with the use of irrigation with a small suction tip in the extraction socket. The Caldwell-Luc operation is used in difficult situations, and it is important to seal the area thoroughly to avoid the formation of fistulas [6].

Received March 15, 2020; Revised [1] April 15, 2020; [2] April 30, 2020; Accepted May 14, 2020

*Corresponding author: Min-Suk Kook, Department of Oral and Maxillofacial Surgery, Dental Science Research Institute, School of Dentistry, Chonnam National University, 42 Jebong-ro, Dong-gu, Gwangju 61469, Republic of Korea.

Tel: +82-62-220-5439, Fax: +82-62-220-5437, E-mail: mskook2@gmail.com 
Oroantral communication can occur during extraction, which implies discontinuity of the tissues. Prolonged oroantral communication can lead to the formation of an epithelial bridge called the oroantral fistula (OAF) [7]. This abnormal communication has multiple causes but is often associated with the extraction of maxillary molars, severe tooth infection, and maxillary sinus pneumatization. Furthermore, implant placement in the maxilla, presence of a cyst or tumor, and trauma can cause an oroantral communication [8].

Small-sized fistulas (1-2 mm) may close naturally; however, large-sized fistulas require oroantral closure. It is recommended to perform the surgery within 24 to 48 hours of formation of an OAF as delayed surgery increases the risk of sinusitis and formation of fistulas due to formation of an epithelial connection [9].

Surgery is essential in cases of accompanied sinusitis and a large perforation $(>5 \mathrm{~mm}$ ). A soft-tissue flap surgery or bone grafting is used. The buccal advancement and palatal rotational flaps are the commonly used soft-tissue flaps. Bone grafting includes an autogenous bone graft, using the iliac bone, an allogenic bone graft, or a synthetic bone graft. These procedures may vary based on the patient' s condition and the surgeon's preference. Furthermore, a soft-tissue flap surgery and bone grafting can be performed simultaneously [10]. In this clinical report, we describe the closure of an OAF using bone fragments of the maxillary sinus collected during extraction of the impacted maxillary premolar.

\section{Case}

A 13-year-old girl was referred for extraction of the left maxillary deciduous second molar (\#65) and impacted left maxillary permanent second premolar (\#25) for an orthodontic treatment. Based on the initial panoramic radiograph and cone-beam computed tomography (CBCT) scan, chronic impaction of tooth \#25 was diagnosed. The premolar was completely dislocated inside the maxillary sinus and present near the nasal cavity and palatal region (Fig. 1).

Extraction of the impacted tooth was initially planned through the tooth socket. After general anesthesia, subcutaneous infiltration of lidocaine with 1:10,000 epinephrine was performed in the vestibules and palate. Tooth \#65 was extracted using forceps, and consecutively, tooth \#25 was extracted through the tooth socket. Manipulation with an elevator was performed for the extractions. However, due to maxillary sinus membrane perforation, an oroantral communication was established, and the tooth fell into the maxillary sinus. To remove the dislocated tooth, the transantral approach was chosen, and a crevicular incision was made involving both the anterior and posterior portions of tooth \#25. Additionally, a vertical incision in the distal portion of tooth \#65 was made to raise a flap.

With an oscillating saw, a rectangular bony window was created, measuring $2 \times 1 \mathrm{~cm}$ and located $3 \mathrm{~mm}$ above the alveolar crest of tooth \#65. Through the window, the dislocated tooth was explored, and it was found at the posterior wall of the maxillary sinus. A thin bone particle was ac-
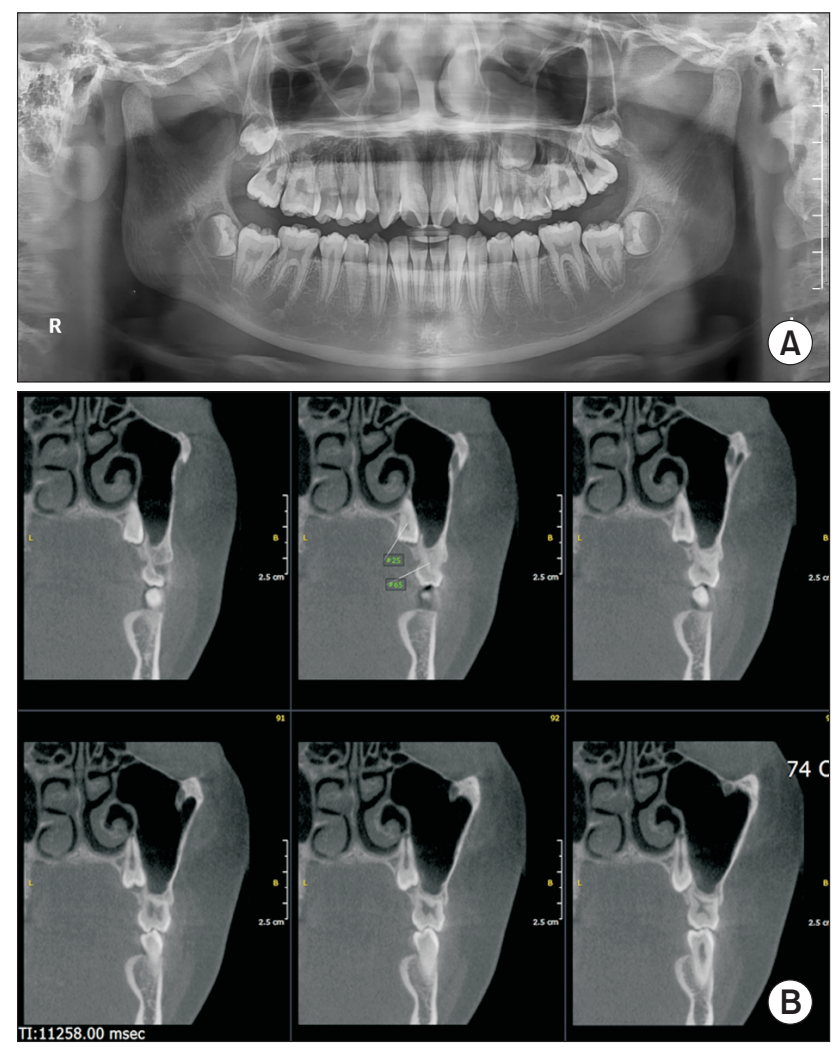

Fig. 1. Preoperative radiograph. (A) Panoramic radiography shows an impacted left maxillary second premolar (\#25) adjacent to the left maxillary sinus and a retained deciduous left maxillary second molar (\#65). (B) Computed tomography scan for the diagnosis shows the impacted tooth \#25 located palatal to tooth \#65 and beneath the nasal floor. 

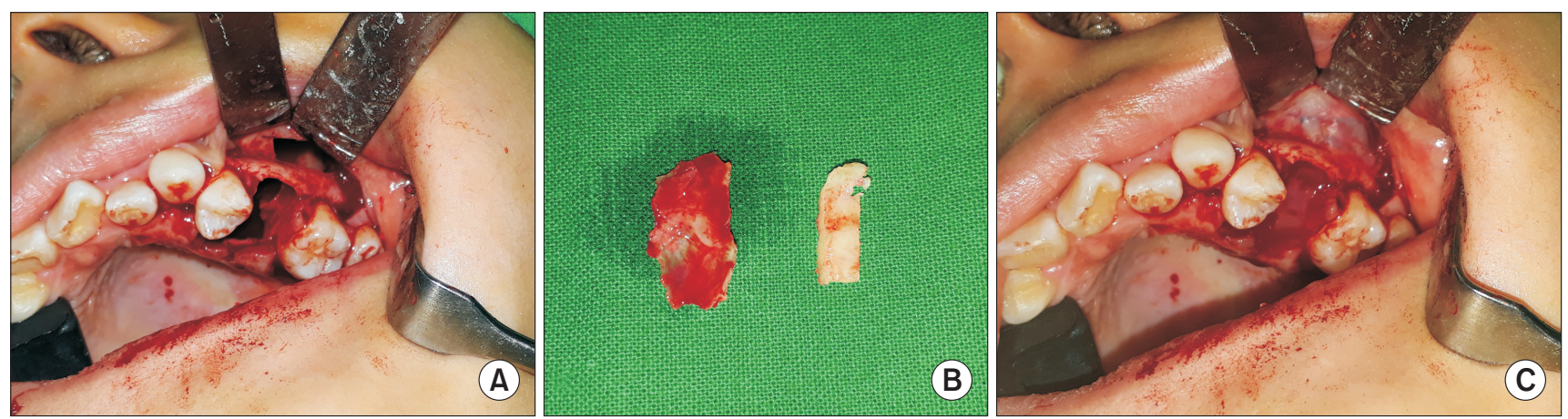

Fig. 2. Intraoperative photograph. (A) Communication between the oral cavity and the left maxillary sinus through the extraction socket is observed. A bony window above the upper left molar is created to explore and remove the dislocated tooth. (B) A bone fragment is acquired during extraction (left), and a bony flap is raised to access the maxillary sinus (right). (C) The bone fragment is placed in the oroantral fistula, and the bony flap is re-positioned. Additionally, fibrin glue is applied in the operation field.

quired while removing the luxated tooth, using a pincette and suction, and it was used to seal the OAF. Through the bony window, the bone fragment was placed at the bottom of the tooth socket to seal the OAF. Subsequently, the bony window was repositioned. Finally, to control hemorrhage and connect the tissues, Greenplast (Green Cross, Yongin, Korea) was placed on the bony window and in the perforated area. A simple interrupted suture with 3-0 Silkam (B. Braun, Seoul, Korea) was performed. Antibiotics for infection, analgesics, anti-inflammatory drugs, and a nasal bleeding mitigator were prescribed for 7 days (Fig. 2).

Five months after the surgery, there were no signs of maxillary sinusitis or fistula on $\mathrm{CBCT}$ or panoramic radiography. Additionally, immature bone had formed in the sealed area where the thin bone fragment was placed (Fig. 3).

\section{Discussion}

Impacted premolars account for approximately $0.5 \%$ of all impacted teeth and are more common in the mandible. If permanent molars are exempted from the statistics, the percentage of second premolar impaction is about 24\% [11]. Impacted teeth require surgical or non-surgical treatment, as they can lead to esthetic issues, inefficient mastication, poor oral hygiene, and cyst formation. Observation and an orthodontic treatment involving surgical exploration and extraction may be conducted for the adjacent teeth.

Displacement of a tooth or its root into the maxillary sinus can occur while extracting maxillary teeth. The max-
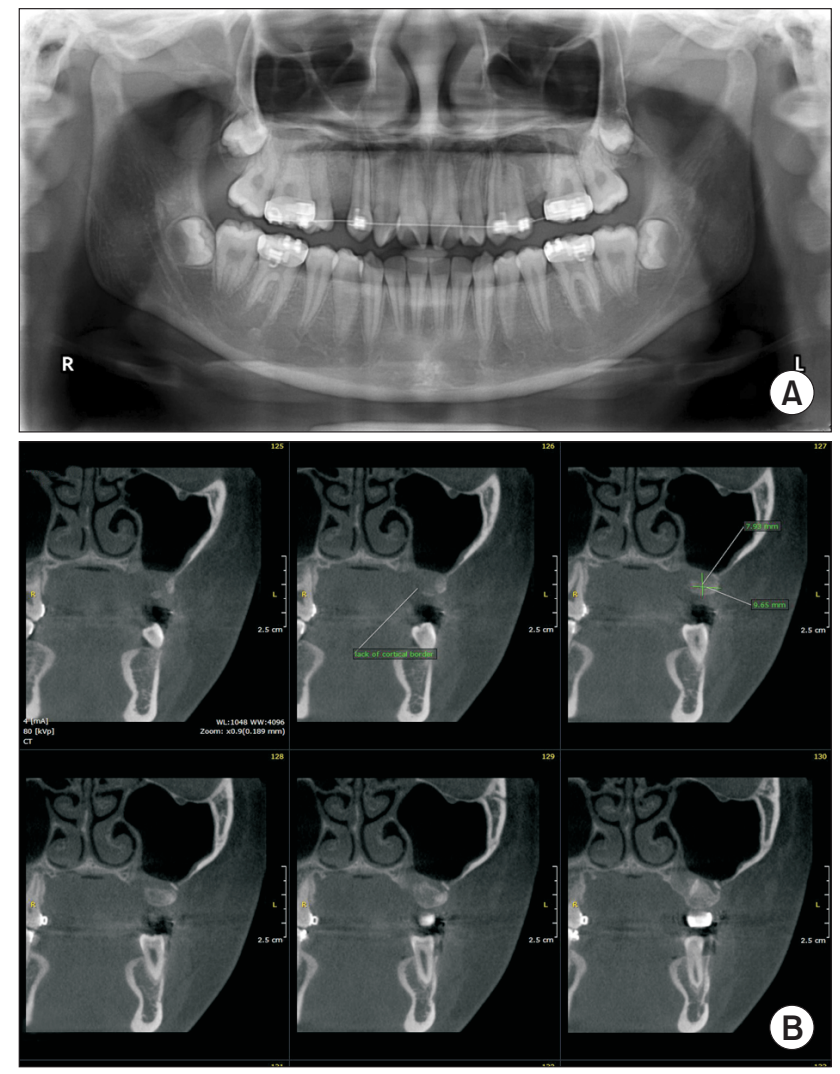

Fig. 3. Postoperative radiograph. (A) Panoramic radiography after 5 months. (B) Computed tomography after 5 months showing no signs of sinusitis.

illary sinus expands with the growth of the skull, and its pneumatization brings it close to the roots of the maxillary teeth, which increases the possibility of perforation and displacement during extraction. Such situations occur 
most commonly during extraction of the maxillary third molars [12]. There is a close association between maxillary sinus perforation and the extraction of both molars and premolars. Particularly, in cases of impaction, perforation, and displacement of molars and premolars are more likely to occur because of their close proximity to the maxillary sinus [13].

The common approaches to remove a displaced tooth and foreign materials from the maxillary sinus are the alveolar crest and transantral approaches. The crestal approach has the advantage of ease of technique, as foreign materials are removed with the use cleansing and suctioning, but the disadvantage of bone loss while enlarging the tooth socket. Although the transantral approach is more invasive than the crestal approach, it has the advantage of a better view and preservation of the alveolar crest. Using an endoscope through the tooth socket, surgeons can not only acquire a better view but also minimize bone loss and tissue damage while removing a displaced implant [14].

When the OAF is larger than $5 \mathrm{~mm}$, aggressive treatment should be performed. There are various materials used for sealing. The use of the iliac bone to block a fistula and emphasized on the ease of acquiring bone fragments and on the efficacy of transplants [15]. By sealing with a bone fragment obtained from the lateral wall of the maxillary sinus, surgeons can achieve better retention using the pressfit technique [16]. Closing of a fistula in the tooth socket with transplantation of the third molar leads to good result and the molar functioned well without root absorption [17]. Using cyanoacrylate adhesive for a large OAF had good outcome without any inflammation [18]. An autogenous cartilage is also a possible graft material for closing fistulas. The auricular conchal and nasal septal cartilages have the least vascularity, so their resorption rates are low [19]. Especially, autogenous bone is the only type of bone having osteogenesis as well as osteoinduction and osteoconduction. It has osteoblasts, osteoclasts, growth factors, and undifferentiated mesenchymal cells facilitating fast bone remodeling process and shows low infection rate [20].

Surgeons cannot achieve a successful closure with rapid healing in cases of sinusitis, regardless of how well the sealing was performed. Mucous exudates of sinusitis are present around the fistula because of gravity and decrease the success of sealing. Therefore, antibiotics and a nasal bleeding mitigator should be prescribed before and after the surgery. Postoperative radiography should be performed to evaluate the signs of sinusitis. Additionally, using fibrin glue directly helps restore the mucous membrane of the maxillary sinus and inhibits the accumulation of inflammatory exudates, which promotes normal functioning of the sinus [21].

\section{Conflicts of Interest}

The authors declare that they have no competing interests.

\section{ORCID}

\author{
You-Song Sim \\ https://orcid.org/0000-0003-1603-3248 \\ Seunggon Jung \\ https://orcid.org/0000-0003-2008-3205 \\ Hong-Ju Park \\ https://orcid.org/0000-0001-7652-5397 \\ Min-Suk Kook \\ https://orcid.org/0000-0002-8053-8534
}

\section{References}

1. Burch J, Ngan P, Hackman A. Diagnosis and treatment planning for unerupted premolars. Pediatr Dent 1994;16: 89-95.

2. Frank CA. Treatment options for impacted teeth. J Am Dent Assoc 2000;131:623-632. doi: 10.14219/jada.archive.2000.0236.

3. Manjunatha BS, Chikkaramaiah S, Panja P, Koratagere N. Impacted maxillary second premolars: a report of four cases. BMJ Case Rep 2014;2014:bcr2014205206. doi: 10.1136/bcr-2014-205206.

4. Mishra R, Tripathi AM, Rathore M. Dentigerous cyst associated with Horizontally impacted mandibular second premolar. Int J Clin Pediatr Dent 2014;7:54-57. doi: 10.5005/ jp-journals-10005-1235.

5. Durmus E, Dolanmaz D, Kucukkolbsi H, Mutlu N. Accidental displacement of impacted maxillary and mandibular third molars. Quintessence Int 2004;35:375-377.

6. Demetoglu U, Ocak H, Bilge S. Closure of oroantral communication with plasma-rich fibrin membrane. J Craniofac Surg 2018;29:e367-e370. doi: 10.1097/SCS.0000000000004360.

7. Yalçın S, Oncü B, Emes Y, Atalay B, Aktaş I. Surgical treat- 
ment of oroantral fistulas: a clinical study of 23 cases. J Oral Maxillofac Surg 2011;69:333-339. doi: 10.1016/ j.joms.2010.02.061.

8. Ramakrishna A, Lambade P. Dentigerous cyst associated with ectopic canine and a supernumerary tooth: a rare occurrence. J Surg Tech Case Rep 2013;5:85-88. doi: 10.4103/2006-8808.128738.

9. Cortes D, Martinez-Conde R, Uribarri A, Eguia del Valle A, Lopez J, Aguirre JM. Simultaneous oral antral fistula closure and sinus floor augmentation to facilitate dental implant placement or orthodontics. J Oral Maxillofac Surg 2010;68:1148-1151. doi: 10.1016/j.joms.2009.09.078.

10. Visscher SH, van Roon MR, Sluiter WJ, van Minnen B, Bos RR. Retrospective study on the treatment outcome of surgical closure of oroantral communications. J Oral Maxillofac Surg 2011;69:2956-2961. doi: 10.1016/j.joms.2011.02.102.

11. Jain U, Kallury A. Conservative management of mandibular second premolar impaction. J Sci Res 2011;4:59-62.

12. Rothamel D, Wahl G, d'Hoedt B, Nentwig GH, Schwarz $\mathrm{F}$, Becker J. Incidence and predictive factors for perforation of the maxillary antrum in operations to remove upper wisdom teeth: prospective multicentre study. $\mathrm{Br}$ J Oral Maxillofac Surg 2007;45:387-391. doi: 10.1016/ j.bjoms.2006.10.013.

13. Amaratunga NA. Oro-antral fistulae--a study of clinical, radiological and treatment aspects. Br J Oral Maxillofac Surg 1986;24:433-437. doi: 10.1016/0266-4356(86)90058-6.

14. Gao QM, Yang C, Zheng LY, Hu YK. Removal of long-term broken roots displaced into the maxillary sinus by endoscopic assistant. J Craniofac Surg 2016;27:e77-e80. doi: 10.1097/SCS.0000000000002235.

15. Proctor B. Bone graft closure of large or persistent oromaxillary fistula. Laryngoscope 1969;79:822-826. doi: 10.1288/00005537-196905000-00005.

16. Er N, Tuncer HY, Karaca C, Copuroğlu S. Treatment of oroantral fistulas using bony press-fit technique. J Oral Maxillofac Surg 2013;71:659-666. doi: 10.1016/j.joms.2012.12.010.

17. Kitagawa Y, Sano K, Nakamura M, Ogasawara T. Use of third molar transplantation for closure of the oroantral communication after tooth extraction: a report of 2 cases. Oral Surg Oral Med Oral Pathol Oral Radiol Endod 2003;95:409-415. doi: 10.1067/moe.2003.122.

18. Choi BH, Kim BY, Huh JY, Lee SH, Zhu SJ, Jung JH, Li J. Cyanoacrylate adhesive for closing sinus membrane perforations during sinus lifts. J Craniomaxillofac Surg 2006;34:505-509. doi: 10.1016/j.jcms.2006.07.859.

19. Kansu L, Akman H, Uckan S. Closure of oroantral fistula with the septal cartilage graft. Eur Arch Otorhinolaryngol 2010;267:1805-1806. doi: 10.1007/s00405-010-1340-x.

20. Kim YK. Bone graft using two types of scaffolds and recombinant human bone morphogenetic protein-2: case series study. Oral Biol Res 2014;38:127-134.

21. Jung HS, Lee CK, Kim YS, Leem DH. Closure of chronic oroantral fistula with repair of the Schneiderian membrane: report of three cases. J Korean Dent Assoc 2016;54:49-56. 